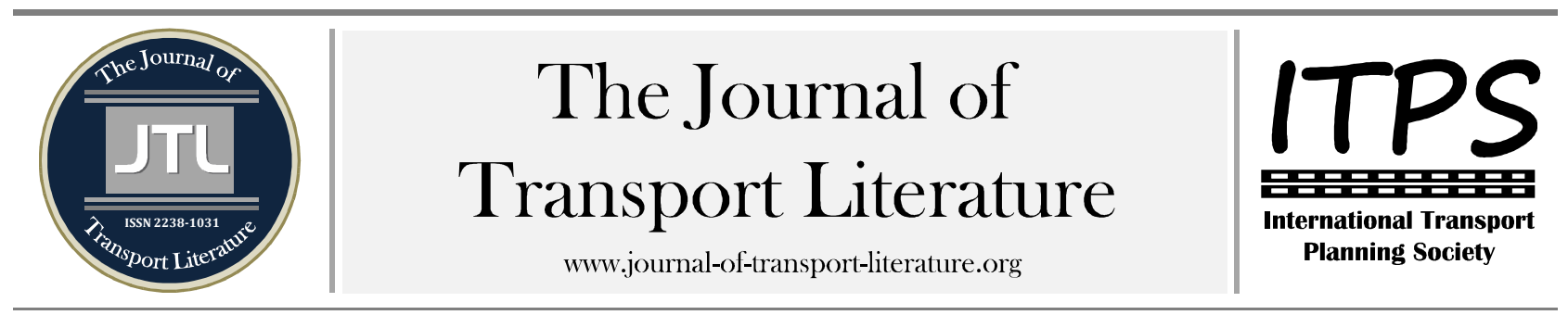

\title{
Analysis of expansions of a bus transit network considering the needs identified by the community: case study
}

Promothes Saha+; Debbie Shinstine

University of Wyoming, Laramie, United States

\section{Article Info}

Keywords:

bus transit

gravity model

expansion analysis

public transportation

Submitted 14 Jul 2014;

received in revised form 1 Dec 2014;

accepted 28 Dec 2014

Licensed under

Creative Commons

CC-BY 3.0 BR.

\section{Abstract}

Expansion analyses are performed on a bus transit network in the City of Laramie area in Wyoming. Expansion analysis is based on the needs identified by the bus transportation agency and the community. This paper examines the expansions, operations and sustainability of a bus transit in a small city having a population of 30,000 people. When funding is limited, it is very important to identify the best route that provides the services to the more people. Gravity model and ArcGIS software have been used to analyze the data. This paper examines the background of the transportation agency and existing services, finally develops a bus routing model for identifying future expansions. This research identified that one of the existing bus stops account for $1 \%$ of the ridership which can be closed. This research also found that adding a new loop considering same number of buses would increase the ridership significantly without increasing headway.

+ Corresponding author. University of Wyoming, 1000 East University Avenue, Laramie, WY 82071 United States.

E-mail address: saha.proms@gmail.com.

\section{Introduction}

The city of Laramie is located in the state of Wyoming and has a population of approximately 30,000 residents. It is estimated that around half of all the people living in Laramie are students of one of three educational institutions. Laramie is home to the University of Wyoming (UW) which is Wyoming's only four year university, a Wyoming Technical Institute campus (WyoTech) that focuses on automotive repair education and a Laramie County Community College (LCCC). In this city, only bus transportation agency: The Albany County Transportation Authority (ACTA) operates the Gem City Grand bus service, the University of Wyoming transit system, the Eppson Center for Seniors transit system and other specialized services for ADA and after hours. The Gem City Grand route provides twelve stops along Laramie's busiest corridor, Grand Avenue, and includes stops at the local Wal-Mart, LCCC, civic center/library, UW and downtown. It runs every 30 minutes from $7 \mathrm{am}-10 \mathrm{pm}$ every day of the week and is free for all residents of Laramie. The major advantage of this route is that it services many of Laramie's local business and attractions. On the downside, the route only runs in an east/west direction so residents that live to the north, south and in West Laramie have no access to public transportation. The ACTA board meets once a month at the city of Laramie conference room. Based on feedback gathered at the meeting it was decided that this project should focus on looking at route expansion alternatives to West Laramie and to expand the existing Gem City Grand route to include northern and southern stops.

The objective of this project is to research the development and operations of ACTA, identify their goals and objectives as well as the challenges they face to sustain their operations. Analyze the current operations of the Gem City Grand service and identify expansions considering the needs identified by the ACTA board and the community. When funding is limited, it is very important to identify the best route that provides the services to the more people. Gravity model and ArcGIS software have been used to analyze the data. This paper examines the background of the transportation agency and existing services, finally develops a bus routing model for identifying future expansions. This research primarily identifies which existing bus stop can be removed based on the percentage of ridership generated and attracted. This research also identifies the possible new routes providing the services to more people considering existing available resources.

Section 1 discusses relevant literature, including bus services in small communities, the challenges and methodology applied to analyze them. Section 2 presents bus routing model used in this research. Section 3 discusses different datasets and sources used in this research, analysis of existing and future conditions, and the possible expansions. Finally, Section 4 summarizes the contributions of this work and key findings and identifies future research directions.

\section{Literature Review}

The technologies, methods and practices for public transportation systems are continually being updated and enhanced. For this reason, background research was conducted which focused on effective transit systems in other college communities, potential models for route selection and sustainability methods of transit systems in rural communities. 
Laramie can best be described as a rural town with a large student population. Two public transportation systems were identified as potential transit models for ACTA since they serve a large student population and have a town of similar size. The first is McDonough County Public Transportation (MCPT) in the town of McComb, Illinois which has a population of 19,280 people and is home to Western Illinois University. This system serves the college campus and the majority of the town of McComb. The city buses run six days a week Monday-Saturday from 7am-7pm during the week and 10am-6pm on Saturday. MCPT is similar to ACTA because it is also a relatively new system. MCPT was started in the late 1990's with only three buses and now operates 15 buses during the peak hour and has a yearly ridership of more than a million people. This system is a great example of what can be achieved by ACTA in the future, through strategic planning and route expansion. (MCPT, 2013). The second system is "MatBus" which serves the North Dakota State University (NDSU) campus and the communities of Fargo/West Fargo, North Dakota and Moorhead/Dilworth, Minnesota. Buses run 6am-10:15pm weekdays and 7am-11:15pm Saturdays on 21 different routes. The service is free for NDSU students and costs $\$ 1.50$ for an adult fare. An interesting aspect of this service is that students scan their ID cards into a farebox when they board the bus. This box does not remove funds from their student account but does insure they are a current student. Even though bus service is currently free for students and residents on the ACTA system, use of fare boxes similar to NDSU may provide a suitable fare collection system should ACTA's financial situation change (MATBUS, 2013).

One of the greatest challenges for a rural transit system is the ability to sustain their operations. Small communities struggle to manage their limited resources and revenues. Taxes, fares and other revenue sources are difficult to obtain community support since the burden is shared by such a small number of people. Most financial support comes from the state and federal government through grants. These funds must be applied for regularly and do not provide a sustained source of revenue. Therefore, a small transit agency must be innovative in finding ways to sustain their operations while providing a much needed service to its citizens.

\section{Bus Routing Model}

This paper presents a routing model that evaluates the performance of the existing and possible future expansions providing services to the increasing number of people without increasing cost. In this research, the traditional four-step transportation model has been evaluated for this transit service. The components of a traditional four-step transportation model include trip generation, trip distribution, mode choice and route assignment. For a bus routing model, trip distribution and route assignment are the components that are emphasized for scheduling and route structuring. The development of a bus service schedule and route structuring is heavily influenced by policies and standards set up by the local government or transit agency (Randall Pine, 1998). However, there are main elements of modeling bus routes that should be considered in conjunction with these policies and standards when developing or evaluating a bus service. Figure 1 identifies these elements which include 1) Identify stop locations, 2) Select shortest path and find cheapest route, 3) Calculate the o-d matrix, 4) Analyze the efficiency of the stops, and 5) Optimize the schedule.

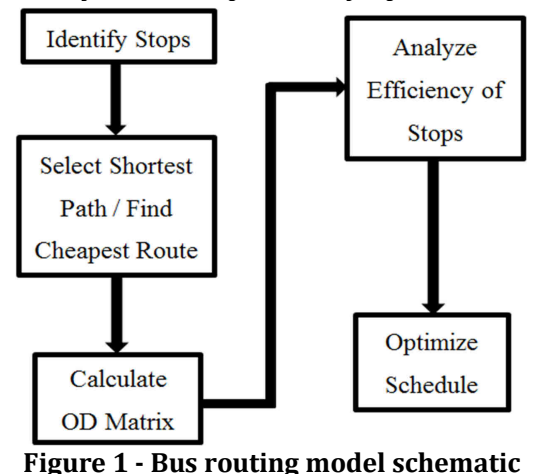

The first step in identifying the stops should include an analysis of the population densities and commercial areas. The densities can be easily extracted from a GIS layer of population by blocks. The commercial areas to be serviced would come from feedback from the community. Once the stops are identified the routing should be optimized by selecting the shortest path and determining the cheapest route. The shortest path problem is one of the most fundamental problems in network optimization. In transportation logistics problems, it can be used to find the cheapest paths connecting each origindestination pair. In designing public transportation routes, the initial step is to find the cheapest path connecting two bus stops. These paths will then be used in determining the best route to connect all bus stops. The two most common approaches for solving shortest paths are label setting and label correcting. Dijkstra's algorithm (Dijkstra, 1959) and the Bellman-Ford algorithm (L.R. Ford, 1962) (Bellman, 1958) are representative label setting and label correcting algorithms that are commonly used. To determine the best bus route in terms of cost, the Traveling Salesman Problem (TSP) can be used. It can be defined as a given list of bus stops, the shortest path between each pair of stops, and determination of the shortest possible route that visits each bus stop exactly once and returns to the original bus stop. The next step is to calculate the Origin-Destination (OD) matrix to determine trip distribution. Trip distribution can be analyzed through the development of such a matrix (Saha, Liu, Melson, \& Boyles, 2014). It is basically a "trip table" that displays the number of trips going from each origin to each destination. The gravity model calculates the trips between origin and destination using the macroscopic relationships between origin and destination.

The gravity model greatly depends on a friction factor formula. It represents the relationship of the distance between each pair of bus stops and the trips. When the distance between each pair of bus stops increases, the trips between them decrease. This equation has a unique derivation for each situation. For the analysis in this report, the following equation (Eq. 1) applies. However, local calibration should be performed in order to provide more accurate results.

$$
\phi\left(L_{i j}\right)=\frac{1}{\mathrm{e}^{-0.03 * \text { Time }_{\mathrm{ij}}}}
$$


Where the average length $L_{i j}$ of a trip between origin $i$ and destination $j$ and Time $_{i j}$ is the average time duration between $i$ and $j . \phi\left(L_{i j}\right)$ indicates the friction factor. According to the gravity model, the formulation of trips is as follows:

$$
d_{i j}=C_{i} R_{b} R_{d b} \phi\left(L_{i j}\right)
$$

Where $d_{i j}$ is the number of trips from origin i to destination j. $R_{b}$ and $R_{d b}$ represent the number of trips boarding and de-boarding at bus stop $i$ and $C_{i}$ is the proportionality constant. Replacing the value of $C_{i}$ :

$$
d_{i j}=\frac{d_{i j} R_{b} R_{d b} \phi\left(L_{i j}\right)}{\sum_{j} R_{d b} \phi\left(L_{i j}\right)}
$$

Several trip tables can be estimated for different times of day. It is common to have an OD matrix for the morning and evening peak hour periods and for the off-peak period. According to ACTA, there are no distinct peak hour periods, so only one OD matrix has been considered for this research. Finally, if actual OD data exists, this matrix can be calibrated.

The final step in the bus route model is to optimize the scheduling. The service frequency and timing can be optimized from the OD matrix. However, many times these are dependent on the local standards and policies set by the board or local government. With the route, stops and headways identified, analysis of alternatives can determine the optimum use of resources to meet the given needs.

\section{Analysis}

The analysis performed for this research was based on feedback from the ACTA board. It starts with a basic analysis of the existing Gem City Grand route to identify inefficiencies in the service. The ACTA board has determined that the existing service could incorporate an additional stop north of downtown at the Gateway Plaza. This addition was then analyzed to determine time and distance for the addition. Then the existing service was analyzed as two loops, north and south. Finally, an additional service to West Laramie was analyzed to determine possible expansion.

\subsection{Existing Service}

The existing Gem City Grand route consists of three buses running east and west from downtown to Wal-Mart with a 30 minute headway. There are currently 13 stops. However, the analysis of the current system will only include 12 stops. Data that was provided for the analysis was collected before the thirteenth stop (Workforce Services) was added. The travel time to transverse the route without stops is 24 minutes for a distance of 5.6 miles. Based on the existing schedule, the total travel time in one direction is 34 minutes, including stops. This allows for an average of 55 seconds per stop. There are three buses running this route with a 30 minute headway which yields a total cycle time of 90 minutes. This allows for a 16 minute layover at Wal-Mart and a 6 minute layover downtown. This time will be useful when analyzing future expansions. A GIS map was created with a radius bubble of 0.25 miles around each stop (Rhonda Daniels, 2011; Walker, 2011). See Figure 2. The area served by Gem City Grand is equal to 1.6 square miles. A similar GIS map was created for the UW transit service with a 0.25 mile radius bubble around each stop. The area served by UW transit is 1.4 square miles. These maps were then overlaid to identify the common areas served. This area is 0.8 square miles which is $50 \%$ of the total area served by Gem City Grand. This overlap identifies inefficiency in the current service and is considered with other factors in the following analysis. The next step in analyzing the existing service is to develop the OD matrix. The boarding and de-boarding information was provided by ACTA which needed to be balanced so the total number of people boarding is equal to the total number of people de-boarding. See Table 1 for the stops and their respective boarding/deboarding numbers (per month) for Gem City Grand. From the existing bus schedule, a distance matrix in travel time (minutes) was created. The OD matrix was developed using the boarding, balanced de-boarding values, and the distance matrix, with the friction factor formula for the gravity model. The gravity model does not balance the boarding/de-boarding values $100 \%$. The boarding values will sum correctly but de-boarding values will adjust to the model. This model produced an error of $11.1 \%$ of the de-boarding values which is within an acceptable range for purposes of this study.

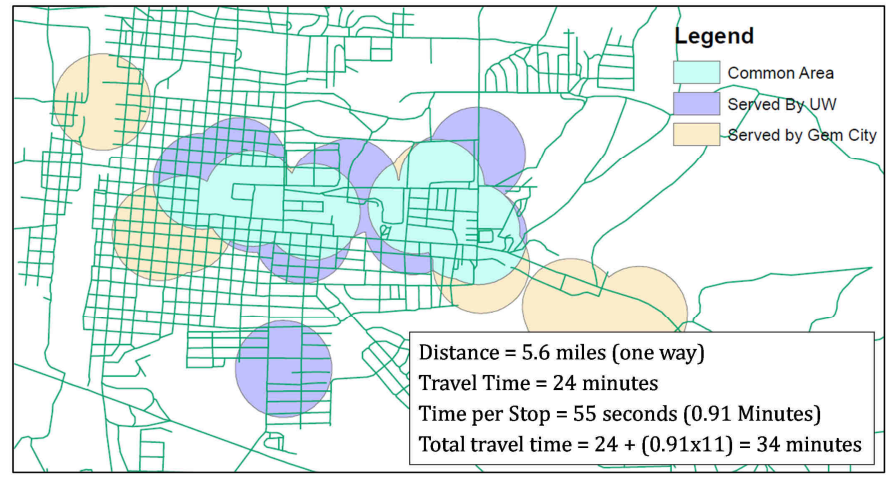

Fig. 2 - Areas served by both Gem City Grand and UW Transit

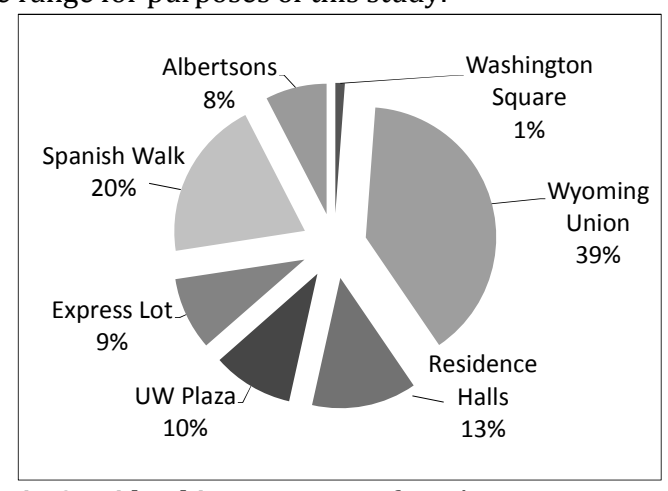

Fig. 3 - Ridership percentages from/to common area

Next the common stops were analyzed within the matrix that are shared between Gem City Grand and UW transit (Table 1). The total ridership within this common area is 1637 of the total 5861 riders on Gem City Grand, which is $28 \%$ of the riders that could be served by UW transit. However, this does not mean that the internal stops can be extracted because there are riders that are not related to the common area bus stops (see shaded area in Table 1). There are riders traveling from outside the common area to the common area and visa-versa. These riders comprise 3226 of the total 5861 riders of the Gem City Grand which is $56 \%$ of total ridership. This should raise some questions on how to improve the service. Which stops are important? Can any be removed? Should any be removed? Figure 3 shows the percentages of riders traveling from/to the common area. Since ACTA wants to remove the stop at the Express Lot, it was examined first. The Express Lot has a ridership of 296 riders, which is $9 \%$ of the riders who takes Gem City Grand to/from Downtown, Civic Center, Rec center, LCCC and Wal-Mart. This would have a considerable impact on the current ridership. However, Washington Square has only 39 riders (1\%) per month. It is also within the 0.25 radius of the Civic Center which serves 655 riders per month. 
Based on this analysis, it is recommended that the Express Lot not be removed from the Gem City Grand route and that Washington Square be removed instead. Furthermore, future analysis of the existing Gem City Grand route should consider winter and summer data separately since Laramie is largely impacted by the university.

Table 1 - Origin-Destination matrix for Gem City Grand Stops (ridership per month)

\begin{tabular}{|c|c|c|c|c|c|c|c|c|c|c|c|c|c|}
\hline & Downtown & $\begin{array}{l}\text { Civic } \\
\text { Center }\end{array}$ & $\begin{array}{c}\text { WA } \\
\text { Square }\end{array}$ & $\begin{array}{l}\text { Wyo } \\
\text { Union }\end{array}$ & $\begin{array}{l}\text { Res. } \\
\text { Halls }\end{array}$ & $\begin{array}{c}\text { UW } \\
\text { Plaza }\end{array}$ & $\begin{array}{c}\text { Express } \\
\text { Lot }\end{array}$ & $\begin{array}{c}\text { Spanish } \\
\text { Walk }\end{array}$ & Albertsons & $\begin{array}{l}\text { Rec. } \\
\text { Center }\end{array}$ & LCCC & $\begin{array}{l}\text { Wal- } \\
\text { Mart }\end{array}$ & Board \\
\hline Downtown & 0 & 24 & 5 & 103 & 51 & 53 & 52 & 120 & 50 & 13 & 83 & 197 & 750 \\
\hline Civic Center & 29 & 0 & 2 & 48 & 24 & 25 & 24 & 56 & 23 & 6 & 39 & 92 & 367 \\
\hline WA Square & 2 & 1 & 0 & 4 & 2 & 2 & 2 & 4 & 2 & 0 & 3 & 7 & 28 \\
\hline Wyo Union & 188 & 71 & 13 & 0 & 100 & 105 & 102 & 238 & 98 & 25 & 163 & 389 & 1492 \\
\hline Res. Halls & 58 & 22 & 4 & 62 & 0 & 27 & 26 & 61 & 25 & 6 & 42 & 99 & 432 \\
\hline UW Plaza & 44 & 17 & 3 & 47 & 20 & 0 & 16 & 36 & 15 & 4 & 25 & 60 & 286 \\
\hline Express Lot & 45 & 17 & 3 & 49 & 20 & 17 & 0 & 31 & 13 & 3 & 22 & 51 & 271 \\
\hline Spanish Walk & 138 & 52 & 10 & 149 & 61 & 50 & 41 & 0 & 33 & 8 & 47 & 100 & 689 \\
\hline Albertsons & 51 & 19 & 4 & 55 & 23 & 19 & 15 & 30 & 0 & 3 & 16 & 35 & 269 \\
\hline Rec. Center & 13 & 5 & 1 & 14 & 6 & 5 & 4 & 7 & 3 & 0 & 4 & 8 & 67 \\
\hline LCCC & 76 & 29 & 5 & 82 & 34 & 28 & 23 & 38 & 15 & 3 & 0 & 42 & 373 \\
\hline Wal-Mart & 185 & 70 & 13 & 200 & 82 & 68 & 55 & 82 & 32 & 7 & 43 & 0 & 837 \\
\hline De-Board & 694 & 288 & 56 & 1015 & 457 & 423 & 377 & 802 & 311 & 73 & 421 & 944 & \\
\hline Calc De-Board & 829 & 327 & 63 & 813 & 423 & 399 & 360 & 703 & 309 & 78 & 487 & 1080 & \\
\hline Error (\%) & 19 & 14 & 13 & 20 & 7 & 6 & 5 & 12 & 1 & 7 & 16 & 14 & $11.1 \%$ \\
\hline
\end{tabular}

\subsection{Future Expansions}

With the recommendations from the existing analysis, the expansion to serve Gateway Plaza was analyzed. Washington Square was removed from the Gem City Grand route for this analysis. The population density maps were obtained from the County planning office to assist in the expansion analysis.

- Gem City Grand Expansion to Gateway Plaza: The first alternative to expand the Gem City Grand service is to extend the current route to include the Gateway Plaza which is north of downtown. This expansion is currently being pursued by ACTA and should be implemented by the end of 2013. The analysis that was performed was to determine the extra travel time needed to add the stop. Since the current schedule has a layover time (16 minutes) at Wal-Mart, the extra travel time needed can be absorbed into the current schedule and the current headways can be maintained. The addition of the Gateway Plaza adds 1.2 miles to the round trip route. The recommendation for this addition is to originate and end at the downtown stop. The total round trip travel time including stops would increase from 68 minutes to 75 minutes. Since the cycle time is 90 minutes, the additional time is easily absorbed in the Wal-Mart layover, reducing it by 7 minutes.

- Gem City Grand Expansion to Two Loops - Alternative 1: The first alternative analyzes the two loops with the north loop providing service to Gateway Plaza and the south loop providing service to Wal-Mart.Transfer locations between the two loops would be the downtown and Albertsons stops. These two routes could be coordinated to maintain the thirty minute headway along Grand Avenue. The north route is 8.5 miles with a total travel time of 45 minutes. The south route is 8.4 miles with a total travel time of 41 minutes. The total miles for the combined routes are 16.9 miles with a total travel time of 86 minutes, which is within the current 90 minute cycle time. To coordinate transfers and maintain a 30 minute headway along Grand Avenue, the two schedules would need to coincide at the downtown and Albertsons stops to allow for transfers. The headways along the north and south route stops would have a one hour headway. This alternative could utilize interlining with the ability to use the third bus. Interlining would also reduce the need for transfer from one route to the next. Current layover times would be absorbed in this alternative.

- Gem City Grand Expansion to Two Loops - Alternative 2: The second alternative analyzes the two loops servicing Gateway Plaza and Wal-Mart. This provides better service because it would eliminate the need to transfer between the two routes to get to Wal-Mart and Gateway Plaza. The same stops are included in alternative 2 as alternative 1 with the addition of the commercial stops. The north route is 11.1 miles with a total travel time of 57 minutes. The south route is 9.5 miles with a total travel time of 47 minutes. The combined distance is 20.6 miles and a total combined travel time of 114 minutes. This is over the 90 minute cycle time so the 30 minute headways cannot be maintained. Interlining could be utilized to balance the cycles of the two loops and the third bus could be used to maintain a 30 minute headway along Grand Avenue. This bus would only run between downtown and Wal-Mart.

- Gem City West Route to West Laramie: The final expansion that ACTA is interested in is a route to West Laramie. West Laramie lies west of the railroad, Laramie River, and Interstate 80. It is somewhat isolated from the rest of Laramie. Based on feedback from the ACTA board and the public through surveys and comments, a route is badly needed to provide alternative transportation modes to this area. West Laramie has a concentration of businesses located along Snowy Range Road, a historic Territorial Prison tourist site, and the Lincoln Civic Center. For this initial analysis the Forest Service was selected as the farthest west stop to provide an easy turnaround. Eventually, service will be provided to the airport which is about 3 miles past the Forest Service. The Territorial Prison is a major tourist attraction and has a large parking lot. It is only open in the summer months. If the UW transit were to consider expansion of their express shuttle service, this would provide for an easy transfer location for transit riders from the Gem City service to the UW service. Therefore, in the summer it would provide access for visitors and in the winter it 
could provide service for the university students. Gateway Plaza is proposed for the first stop and would provide transfer service to Gem City Grand. Gateway Plaza is also conveniently close to one of the two viaducts over the railroad. The total length of the route would initially be 6 miles with a total travel time of 28 minutes. This would work well to coordinate with the Gem City Grand at the Gateway Plaza, providing a cycle time of 60 minutes, with a 4 minute layover at the Gateway Plaza. If the Gem City Grand Service were altered to a two loop system with one hour cycle times, the three routes could coordinate stops at the Gateway Plaza, providing service throughout Laramie. This would allow ACTA to expand service to a larger portion of Laramie without expanding their fleet.

\section{Conclusion}

The main objective of this research was to research the development and operations of ACTA and to identify their goals and challenges for operations. The research team attended an ACTA board meeting on March 26th, 2012. Based on their feedback, the research team decided to analyze the current operations of the Gem City Grand service and identify potential expansions to serve the northern and southern areas of Laramie and the community of West Laramie. The existing Gem City Grand bus route runs east and west between downtown and Wal-Mart. It includes three buses having a headway of 30 minutes and a cycle time of 90 minutes. With layover time at the downtown and Wal-Mart stops, there is room for expansion within the existing service. ACTA is considering removing the East Express lot stop. However, this analysis shows that this stop provides 9\% of the ridership taking Gem City Grand to/from downtown, civic center, rec center, LCCC and Wal-Mart. Whereas, the Washington Square stop only accounts for $1 \%$ of the ridership and only has 39 riders per month. Additionally, Washington Square is within a 0.25 mile radius of the Civic Center which serves 655 riders per month that travel to/from the common area. It is recommended that the East Express lot not be eliminated and that the Washington Square stop be eliminated instead since riders can use the Civic Center stop. Expanding service to the Gateway Plaza can easily be accommodated within the current service maintaining the 30 minutes headways and 90 minute cycle times. With the existing route and adding a loop to the Gateway Plaza from downtown, the Wal-Mart layover will be reduced from 16 minutes to 9 minutes.

Two alternatives were analyzed to modify the existing Gem City Grand to a 2-loop system, providing service to the north and south areas of Laramie. Both alternatives could possibly be accommodated within the existing operations, since the same number of buses and operating times could be used. The first alternative considers the north loop providing service to the Gateway Plaza and the South Loop providing service to Wal-Mart. This would require transfers at the downtown and Albertsons stops. However, possible interlining would reduce the need for transfers but would require riders to ride longer trips. The total travel time for the two loops is 86 minutes. Since this is within the current cycle time, the schedule could be coordinated to maintain the 30 minute headways. The second alternative considers both loops providing service to Gateway Plaza and Wal-Mart, which would eliminate the need for transfers for riders from either loop to access these commercial stops. The total travel time for the two loops is 114 minutes. This exceeds the 90 minute cycle time which could not accommodate a 30 minute headway. The two loops could be interlined to balance the cycle time and the third bus used along the existing route between Wal-Mart and downtown to maintain ta 30 minute headway. Finally, a West Laramie route was analyzed. A route was considered that includes stops at the Territorial Prison and the Lincoln Civic Center and extending as far as the Forest Service with commercial stops in between. With the route originating at the Gateway Plaza, it could provide transfer service to the other routes. The initial route would require a 60 minute cycle time. Since ACTA's first priority in expanding service is to West Laramie, it is feasible to consider adding it to the current service. This can be done by utilizing the two-loop Gem City Grand route with 60 minute cycle times for each loop using only two buses and using the third bus for the Gem City West route. This would allow for expansion to a greater area of Laramie within the existing operations. However, this would increase waiting times for riders.

This research could serve as an extra resource to the ACTA board when considering their current service and future route expansions. The analysis is based on limited ridership information received from ACTA and applies some theoretical modeling. Caution should be used for any decisions that would be based on this report. As ACTA continues to collect actual ridership data, more thorough analysis could be completed. It is recommended that the proposed methodology for analyzing a small transit service should be implemented in a small community like Laramie, WY. This analysis is based on the current conditions of the ACTA transit service and the needs of the community. Indicators used in this research are travel times between bus stops, ridership at each bus stop and demographics. It is also recommended that additional sources of data, such as walking distance from origin/destination to bus stops be incorporated in the model in the future to increase the accuracy of the results.

\section{References}

ACTA (2012). Albany County Transit 5 Year Plan, Fiscally uncontrained, Laramie, Wyoming.

Bellman, R. (1958). On a routing problem. Quarterly of Applied Mathematics, 16, 87-90.

Dijkstra, E. (1959). A note on two problems in connexion with graphs. Numerische Mathematik, 1, $269-271$.

L.R. Ford, J. A. (1962). Flows in Networks. Princeton University Press.

Laramie Boomerang. (2011). County Approves Resolution For Transit Authority. Retrieved from www.laramieboomerang.com.

MATBUS (2013). Metro Area Transit. Retrieved from Go Green, Ride With US! Retrieved from www.matbus.com.

MCPT (2013). McDonough County Public Transportation. Retrieved from Get Where You're Going. Retrieved from www.837ride.com.

Randall Pine, J. N. (1998). Report 30, Transit Scheduling: Basic and Advanced Manuals.

Saha, P., Liu, R., Melson, C., \& Boyles, S. (2014). Network Model for Rural Roadway Tolling with Pavement Deterioration and Repair. Computer-Aided Civil and Infrastructure Engineering, 29, 315-329.

Rhonda Daniels, C. M. (2011). Explaining walking distance to public transport: the dominance of public transport supply. World Symposium on Transport and Land Use Research. Whistler Canada.

Walker, J. (2011). Human Transit: Basics: walking distance to transit. Retrieved from www.humantransit.org. 